\title{
PHONON DISPERSION IN Cu-Zn ALLOY
}

\author{
I. AKgüN \\ Gazi University, Faculty of Arts and Sciences, 06500 Ankara, Turkey
}

(Received March 25, 1993)

\begin{abstract}
Phonon dispersion curves for fcc $\mathrm{Cu}-25 \% \mathrm{Zn}$ alloy were calculated using deLauney angular force model, the analysis being limited to the second neighbour interactions only. In the present calculations the elastic constants of $\mathrm{Cu}$ and $\mathrm{Zn}$ in fcc and hcp phases, respectively, were used to evaluate the force constants of the alloy system. Satisfactory agreement between theory and experiment is obtained.
\end{abstract}

PACS numbers: 63.20.-e

\section{Introduction}

In recent years there have been growing efforts in the study of the vibrational spectra of binary alloys of the type $A_{1-x} B_{x}$ [1-3]. In addition to providing information about the lattice dynamics of particular alloys, the study of alloy systems has the following advantage: making a proper choice of constituents and concentrations, various factors affecting the lattice dynamics of metals such as conduction electron concentration or force constant changes may be investigated separately. Using inelastic scattering of neutrons, the phonon dispersion curves of $\mathrm{Cu}-25 \% \mathrm{Zn}$ alloy are observed by Hallman and Brockhouse [4]. The interesting feature of $\mathrm{Cu}-\mathrm{Zn}$ alloy is that the two constituents of the alloy are in different phases, as $\mathrm{Cu}$ is in fcc phase and $\mathrm{Zn}$ in hcp phase. However, if the alloy is prepared at a particular concentration $(0<x \leq 39)$ a single homogeneous crystal is formed having a unique fcc lattice [5]. Due to their structural complexes, not much theoretical work is done on $\mathrm{Cu}-\mathrm{Zn}$ alloys. In the present paper, therefore, the phonon dispersion in $\mathrm{Cu}-25 \% \mathrm{Zn}$ alloy is theoretically investigated. The DAF (deLauney angular force) model [6] has been used to calculate the phonon frequencies of the alloy, the analysis is limited to the second neighbour interactions only. The force constants for the end members have been evaluated in their original structures, from the elastic constants measured for $\mathrm{Cu}$ and $\mathrm{Zn}$ in fcc and hcp phases, respectively. The linear variation of these force constants with concentrations has been considered for the mixed alloy. With the help of such force constants the results of phonon dispersion of $\mathrm{Cu}-25 \% \mathrm{Zn}$ in fcc phase are presented. The calculated frequencies are in satisfactory agreement with the experimental ones. 


\section{Theory}

The alloy $\mathrm{Cu}-25 \% \mathrm{Zn}$ forms a random solution having a fcc structure [5]. In such a case the matrix equation which determines the dispersion relation is given by

$$
\left|P_{i j}-M W^{2} I\right|=0,
$$

where $i, j=1,2,3 ; I$ is the unit matrix, $W$ is the frequency and $M$ is the mass of the alloy $\left(M=0.75 M_{\mathrm{Cu}}+0.25 M_{\mathrm{Zn}}\right)$. The typical expressions of the dynamical matrix in DAF model for fcc structure [7] are

$$
\begin{aligned}
& P_{11}=4 \alpha_{1}+8 \alpha^{\prime}-2\left(\alpha_{1}+\alpha^{\prime}\right) c_{1}\left(c_{2}+c_{3}\right)-4 \alpha^{\prime} c_{2} c_{3}+4 \alpha_{2} s_{1}^{2}+4 \alpha^{\prime \prime}\left(s_{2}^{2}+s_{2}^{3}\right), \\
& P_{12}=2\left(\alpha_{1}-\alpha^{\prime}\right) s_{1} s_{2},
\end{aligned}
$$

where $c_{i}=\cos \left(\pi a k_{i}\right)$ and $s_{i}=\sin \left(\pi a k_{i}\right) ; i=1,2,3$. Here $\alpha_{1}, \alpha_{2}$ are the central force constants and $\alpha^{\prime}, \alpha^{\prime \prime}$ are the angular force constants up to the second nearest neighbour for the alloy system.

The force constants involved in the dynamical matrix of the binary fcc alloy can be related to the force constants of $\mathrm{Cu}$ and $\mathrm{Zn}$ by the linear relation

$$
\alpha_{\text {alloy }}=0.75 \alpha_{\mathrm{Cu}}+0.25 \alpha_{\mathrm{Zn}} \text {. }
$$

In order to determine the force constants of pure $\mathrm{Cu}$ and $\mathrm{Zn}\left(\alpha_{\mathrm{Cu}}\right.$ and $\alpha_{\mathrm{Zn}}$, respectively) the measured elastic constants for fic Cu and hcp $\mathrm{zh}$ were used.

For fcc $\mathrm{Cu}$ the three elastic constants and the longitudinat phonon frequency $i \nu_{\mathrm{b}}$ in the [100] direction $\left(\nu_{\mathrm{b}}=7.21 \times 10^{13} \mathrm{~Hz}[8]\right)$ at the zone boundary are related to the four force constants as follows [7]:

$$
\begin{aligned}
& a C_{11}=2 \alpha_{1}+2 \alpha^{\prime}+4 \alpha_{2}, \\
& a C_{12}=\alpha_{1}-5 \alpha^{\prime}-4 \alpha^{\prime \prime}, \\
& a C_{44}=\alpha_{1}+3 \alpha^{\prime}+4 \alpha^{\prime \prime}, \\
& M H_{6}^{\prime}-8 \alpha_{1}+8 \alpha^{\prime},
\end{aligned}
$$

where $a$ is the lattice parameter. The input data are given in Table I. For copper the force constants determined from the above equations are given in Table II.

Input data. Elastic constants in units of $\left[10^{12} \mathrm{dyn}^{-2}\right]$.

\section{TABLE I}

\begin{tabular}{l|c|l|l|l|c|c|c}
\hline \hline Element & $M$ [a.m.u.] & $C_{11}$ & $C_{12}$ & $C_{44}$ & $C_{33}$ & $a\left[10^{-8} \mathrm{~cm}\right]$ & $c\left[10^{-8} \mathrm{~cm}\right]$ \\
\hline Cu [4] & 63.54 & 1.685 & 1.215 & 0.755 & - & 3.615 & - \\
Zn [12] & 65.38 & 1.650 & 0.310 & 0.396 & 0.620 & 2.66 & 4.95
\end{tabular}

For hcp $\mathrm{Zn}$ the four elastic constants $C_{11}, C_{12}, C_{33}$, and $C_{44}$, as given in Table I, are related to the four force constants as follows [9]:

$$
\begin{aligned}
C_{11} & =(2 \sqrt{3} / c)\left\{(1 / 4)\left(3 \alpha_{2}+\alpha^{\prime \prime}\right)\right. \\
& \left.+\left[2 \alpha^{\prime}+\left(\alpha_{1}-\alpha^{\prime}\right)^{2} / n+\alpha^{\prime}\left(\alpha_{1}-\alpha^{\prime}\right) / n\right] /\left[6 \alpha^{\prime}+3\left(\alpha_{1}-\alpha^{\prime}\right) / n\right]\right\}
\end{aligned}
$$


TABLE II

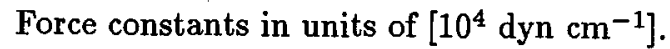

\begin{tabular}{c|c|c|r|c}
\hline \hline System & $\alpha_{1}$ & $\alpha_{2}$ & \multicolumn{1}{|c|}{$\alpha^{\prime}$} & \multicolumn{1}{c}{$\alpha^{\prime \prime}$} \\
\hline $\mathrm{Cu}$ & 3.132 & 0.171 & -0.428 & 0.221 \\
$\mathrm{Zn}$ & 0.560 & 3.068 & 0.283 & 0.120 \\
$\mathrm{Cu}-25 \% \mathrm{Zn}$ & 2.489 & 0.895 & -0.250 & 0.196
\end{tabular}

$$
\begin{aligned}
C_{11} & -C_{12}=(2 \sqrt{3} / c)\left\{(1 / 2)\left(\alpha_{2}+3 \alpha^{\prime \prime}\right)\right. \\
+ & {\left.\left[4 \alpha^{\prime 2}+3 \alpha^{\prime}\left(\alpha_{1}-\alpha^{\prime}\right) / n\right] /\left[6 \alpha^{\prime}+3\left(\alpha_{1}-\alpha^{\prime}\right) / n\right]\right\}, } \\
C_{33}= & \left(c \sqrt{3} / 2 a^{2}\right)\left\{2 \alpha^{\prime}+\left(3 c^{2} / 2 a^{2}\right)\left[\left(\alpha_{1}-\alpha^{\prime}\right) / n\right]\right\}, \\
C_{44}= & \left(c \sqrt{3} / 2 a^{2}\right)\left[2 \alpha^{\prime}+\left(\alpha_{1}-\alpha^{\prime}\right) / n\right],
\end{aligned}
$$

where $n=1+\left(3 c^{2} / 4 a^{2}\right)$, and $c, a$ are the lattice parameters. The solution of these equations determines the force constants of $\mathrm{Zn}$ as given in Table II. Knowing the force constants of $\mathrm{Cu}$ and $\mathrm{Zn}$, respectively, and using the linear relation (3), it is possible to determine the force constants of fcc $\mathrm{Cu}-25 \% \mathrm{Zn}$ alloy. These force constants are substituted in the dynamical matrix equations (1) and (2) to find out the frequencies for selected values of phonon wave vector in symmetry directions.

\section{Results and discussion}

For $\mathrm{Cu}-25 \% \mathrm{Zn}$ alloy the dispersion curves obtained by utilizing the above model are shown in Fig. 1. The figure exhibits satisfactory agreement with the experimental results. The agreement obtained between theory and experiment reveals that the angular forces play an important role in $\mathrm{Cu}-\mathrm{Zn}$ alloy. However, any input data of the fcc $\mathrm{Cu}-25 \% \mathrm{Zn}$ alloy were not used in the present results and even then using only the input data of $\mathrm{Cu}$ and $\mathrm{Zn}$, respectively, in their original structures, there is good agreement in all symmetry directions.

Recently, the phonon dispersion relations for In-Tl alloy [10] has been explained satisfactorily with the model described above. The structures of the two end members were tetragonal for indium and hexagonal closed-packed for thallium, respectively, and finally fcc for $\mathrm{In}-24 \% \mathrm{Tl}$ alloy [11]. The input data was taken from the original structures of In and $\mathrm{Tl}$ and the force constants were evaluated assuming a linear relation. These force constants gave a satisfactory description of phonon dispersion for $\mathrm{fcc} \mathrm{In}-\mathrm{Tl}$ alloys. It proves that the model suggested above can explain the thermal properties of the alloy systems where the end members have different structures being different from the mixed binary alloy structure. 


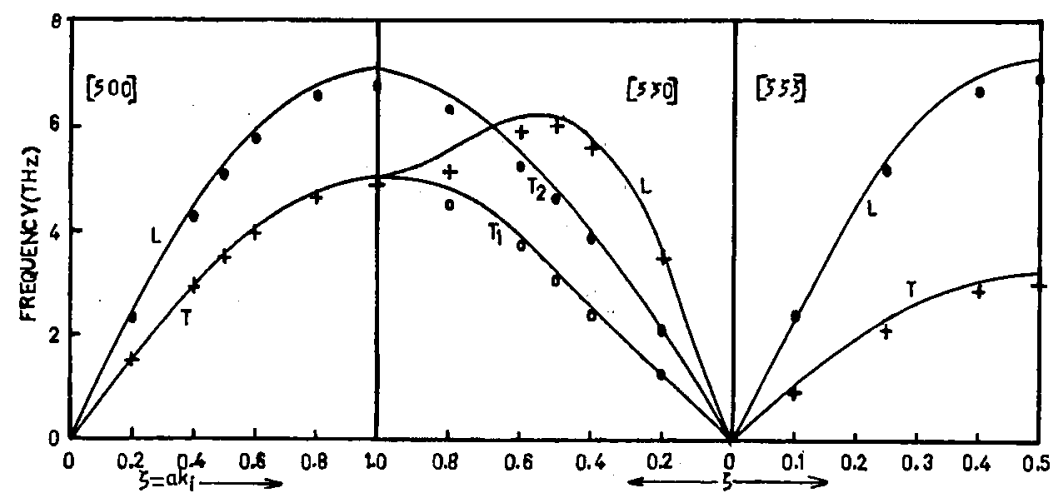

Fig. 1. Phonon dispersion curve at room temperature for $\mathrm{Cu}-25 \% \mathrm{Zn}$. The symbols $(o, \bullet,+)$ represent the experimental findings [4]. The solid curves show the calculated frequencies.

\section{References}

[1] W.A. Kamitakahara, J.R.D. Copley, Phys. Rev. B 18, 3772 (1978).

[2] M. Sato, B.H. Grier, S.M. Shapira, H. Miyajima, J. Phys. F 12, 2117 (1982).

[3] S. Garg, H.C. Gupta, B.B. Tripathi, Solid State Commun. 51, 41 (1984).

[4] E.D. Hallman, B.N. Brockhouse, Can. J. Phys. 47, 1117 (1969).

[5] M. Hansen, Constitution of Binary Alloys, McGraw-Hill, New York 1958.

[6] J. deLauney, Solid State Phys. 2, Academic Press, New York 1956, p. 219.

[7] G. Bose, H.C. Gupta, B.B. Tripathi, J. Phys. F, Metal Phys. 2, 426 (1972).

[8] A.P. Miller, B.N. Brockhouse, Can. J. Phys. 49, 704 (1971).

[9] G. Bose, B.B. Tripathi, H.C. Gupta, J. Phys. Soc. Jpn. 34, 1006 (1973).

[10] S. Garg, H.C. Gupta, B.B. Tripathi, Solid State Commun. 56, 519 (1985).

[11] T.R. Finlayson, M. Mostoller, W. Reichardt, H.G. Smith, Solid State Commun. 53, $461(1985)$.

[12] G. Simmons, H. Wang, Single-Crystal Elastic Constants and Calculated Aggregate Properties, A Handbook, MIT Press, Cambridge 1971. 